\title{
Inicios da galeguización do ensino (1963-1977) ${ }^{1 *}$
}

\author{
The beginnings of the Galician Language introduction into the \\ teaching (1963-1977)
}

\author{
María Dolores VILLANUEVA GESTEIRA \\ Universitat de Barcelona
}

\begin{abstract}
RESUMO: "Inicios da galeguización do ensino (1963-1977)". Este artigo pretende ofrecer unha panorámica dos movementos que os axentes civís e as institucións galegas levaron a cabo para conseguir que se implantara o galego no ensino. Entre 1963 e 1977 as asociacións culturais ofreceron cursos para adultos e introduciuse o galego na Universidade de Santiago de Compostela, pero resistíase a incursión do estudo da lingua no ensino obrigatorio e no bacharelato. A Real Academia Galega comeza as xestións, ó igual que a Euskaltzaindia e 0 Institut d'Estudis Catalans, co Ministerio de Educación e Ciencia. A Lei Xeral de Educación (1970) recolle a posibilidade de introducir as linguas diferentes do castelán no ensino, aínda que habería que agardar ó Decreto 1433/1975 para que se desenvolva máis este aspecto. Este feito supón un gran avance, aínda que non cumpría tódalas expectativas e as reivindicacións seguen nos anos seguintes.
\end{abstract}

PALABRAS CHAVE: galeguización, reivindicacións, asociacionismo, iniciativas civís e institucionais, cursos de galego.

ABSTRACT: "The beginnings of the Galician Language introduction into the teaching (19631977)". This article wants to offer an overview regarding the steps taken by the Galician Civil Agents and Institutions in order to introduce the Galician language into the education. Between 1963 and 1977 the Cultural Associations offered courses for adult people and the Galician Language was introduced into the University of Santiago de Compostela, but there were still difficulties in order to set the studies of the language both in the compulsory education and at the Bachelor's degree Studies. The Galician Royal Academy (Real Academia Galega) started its negotiations, as well as the Euskaltzaindia and the Institut d'Estudis Catalans did, with the Ministry of Education and Science. The General Act of Education (1970) brings the possibility of introducing those of the languages different than Spanish into the teaching, however it will not be until the executive order 1433/1975 that this matter would be more developed. This fact

1 *Este artigo non sería posible sen as facilidades da Euskaltzaindia (a Academia da Lingua Vasca) na localización dos documentos, que me enviaron con moita dilixencia e amabilidade. O meu agradecemento tamén para a Real Academia Galega e a Fundación Penzol por poñer á miña disposición a documentación requirida. 
means a great step forward, even though it will not satisfy the expectations and there will be more claims during the following years.

KEY WORDS: Galician Language introduction into teaching, claims, associationism, Civil and Institutional initiatives, courses of Galician language.

Nos anos sesenta a educación en Galicia seguía a ser moi precaria, atrasada e con escasos resultados debido, en boa medida, a que o sistema estaba pouco implantado 2 . Nesa década o Réxime fascista coñece un período de apertura, propiciado pola entrada en 1957 do "goberno tecnócrata», que promove un incipiente desenvolvemento económico, grazas ó asentamento dalgunhas empresas nas cidades ou á aprobación do Plan de estabilización en 1959, co que se eliminaban algúns controis e barreiras que favorecían a integración da economía española no ámbito internacional. Mentres isto acontecía, a sociedade galega seguía a ser eminentemente rural, porque a transformación sectorial que se estaba a producir no resto do Estado, chegaba tarde a Galicia e con pouco pulo. Só o 15\% da poboación activa en 1975 estaba empregada na industria, unha cifra non moi superior ó $11,3 \%$ de 1960. Un avance moi discreto que nos debuxa un escenario económico pouco desenvolvido, cunha actividade industrial baixa, en confronto ó resto de España, e cunha economía pouco activa.

A lingua habitual de máis de tres cuartos da poboación seguía a ser o galego, tendo en conta os resultados do Mapa sociolingüístico de Galicia ${ }^{3}$, pero as pequenas mudanzas socioeconómicas tiveron consecuencias nos hábitos lingüísticos e comezan nesta década a emerxer pautas diglósicas vinculadas ós desprazamentos do campo á cidade, ós cambios de ocupación profesional ou ó maior acceso á educación. Aínda así, o galego seguía a ser o idioma inicial de gran parte das persoas que naceran en localidades rurais, a do $85,8 \%$, fronte á de só un 16,7\% nas cidades. Non só estaba asociado ás comunidades rurais senón tamén a estratos sociais máis desfavorecidos. Así, o 75,3\% das persoas pertencentes á clase social baixa tiña como lingua inicial o galego, fronte ó $28,1 \%$ da clase media-alta. A clase social remite sempre ó poder económico e, polo tanto, leva aparellados outros parámetros, coma o feito de que o galego fose a lingua inicial do $92,6 \%$ da poboación que carecía de estudos e só a do 19,1\% dos licenciados universitarios. Se analizamos nesta década as destrezas comunicativas para o galego, observamos que, no momento en que era a lingua da maior parte da poboación, un $61,5 \%$ das persoas enquisadas aseguraban non saber ler en galego e a cifra aumentaba se a competencia era activa, pois $082,5 \%$ recoñecía non poder escribir en galego.

2 Unha visión de conxunto para Galicia pode verse en A. COSTA RICO, Historia da educación e da cultura en Galicia (Séculos IV-XX), Edicións Xerais, Vigo, 2004.

3 Para unha análise máis pormenorizada destes datos poden verse: M. FERNÁNDEZ RODRíGUEZ e M. RODRÍGUEZ NEIRA (coords.), Lingua inicial e competencia lingüística en Galicia. Real Academia Galega, Seminario de Sociolingüística, A Coruña, 1994; M. A. FERNÁNDEZ RODRÍGUEZ e M. RODRÍGUEZ NEIRA (coords.), Usos lingüisticos en Galicia. Compendio do II Volume do Mapa Sociolingüístico de Galicia, Real Academia Galega, Seminario de Sociolingüística, A Coruña, 1995; M. A. RODRíGUEZ NEIRA (coord.), Mapa sociolingüístico de Galicia 2004. Volume I. Lingua inicial e competencia lingüística en Galicia. Real Academia Galega, Seminario de Sociolingüística, A Coruña, 2007. 
Galicia seguía atrasada economicamente e os postos máis cualificados ocupábanos unha maioría castelanfalante. A dignificación do idioma propio de Galicia foi unha angueira común dunha parte da intelligentsia galega, pero será nesta década cando se avance cara á presenza do galego en ámbitos que lle foran vetados. Vanse aproveitar as pequenas fendas lexislativas que permitía o réxime, nun momento en que o dique de censura e terror levantado a partir de 1936 xa non podía deter a marea de iniciativas sociais.

$\mathrm{Na}$ década dos sesenta levedan diferentes asociacións culturais 4 , que están na base da formación de partidos políticos coma o Partido Socialista Galego (PSG) ou a Unión do Pobo Galego (UPG). Buscaban intervir na sociedade a través de canles culturais, pero sempre coa idea de espertaren un país narcotizado polo fascismo, de divulgaren ideas progresistas e de valorizaren a cultura e a lingua propias. Fixérono coa promoción de actividades moi diversas, que pretendían penetrar nunha sociedade moi desestruturada e moi asoballada. Será neste momento cando se realicen concursos literarios, moitos deles con grande éxito, coma o Premio de Teatro Castelao, impulsado pola Asociación O Galo, creada en Santiago de Compostela en 1961; ou os concursos de contos e de teatro infantís que botaron a andar dende a Agrupación Cultural O Facho, fundada na Coruña en 1963. Non só se promoveron iniciativas literarias, senón que furgaron tódolos camiños posibles, tamén o das ondas radiofónicas, e así a Asociación Cultural de Vigo, nada en 1965, chegou ás casas da cidade grazas á emisión do primeiro programa de radio en lingua galega en España despois do ano 1936. Tódolos vigueses podían escoitar semanalmente nas ondas de La Voz de Vigo o programa Raíz e tempo. Estas tres asociacións son quizais as máis significativas, pero proliferaron outras moitas que seguiron o mesmo camiño de fomento do galego. Unha das campañas con máis divulgación foi a que levou a cabo esta asociación viguesa, pois imprimiron 2.000 adhesivos co lema "Falemos galego", que encheron Galicia grazas á colaboración coa Agrupación Cultural O Facho e coa Agrupación Cultural Auriense. Como tiveron moita repercusión, houbo unha nova fornada de adhesivos, nesta ocasión coa frase "Galego na escola". Ese slogan resume ben unha das peticións constantes deste período e unha das batallas nas que gastaron moitos esforzos para que cristalizase.

No inverno de 1964 comezaba en Santiago de Compostela o curso de lingua galega impartido por Manuel Vidán Torreira e organizado pola Asociación Cultural O Galo. Un ano despois trasladouse da Academia Minerva á biblioteca do Instituto Padre Sarmiento de Estudios Gallegos e, desta volta, foi impartido por Antón Santamarina. Nese mesmo ano tamén a Agrupación Cultural Os Novos, de Pontevedra, contribuíu á difusión do galego cun curso a cargo de Agustín R. Caamaño, e o escritor A. López Casanova fixo o propio en Lugo, desta vez grazas ó apoio do Grupo Cultural Ronsel. En setembro dese mesmo ano 1964 O Facho ofreceu durante un mes un curso na sala de exposicións da Casa da Cultura, dado por Leandro Carré Alvarellos, e que tería continuidade ó ano seguinte, desta vez

40 labor do asociacionismo en Galicia nesta etapa aínda non está estudado con toda a profusión que require o tema, aínda que nos últimos anos se levaron a cabo intentos serios, como pode verse en R. GURRIARÁN (coord.), Un canto e unha luz na noite. Asociacionismo cultural en Galicia (1961-1975), Consello da Cultura Galega-Fundación 10 de marzo, Santiago de Compostela, 2012. Sobre O Facho véxase VV.AA, A Coruña na cultura galega. Agrupación Cultural O Facho, Venus Artes Gráficas, A Coruña, 1991. 
dende 02 de novembro ata maio ${ }^{5}$, da man de Xosé Luís Rodríguez Pardo. 0 interese ía en aumento e así no curso 1967-68 víronse obrigados a facer dous grupos para dar resposta á demanda e na quinta edición, debido ó número de participantes, as clases estiveron a cargo de Manuel Vidán Torreira, pero auxiliado por Luz Pozo Garza, Xosé Manuel Rodríguez Pampín e Ramón Fraga García. Estes cursos contaban en moitos casos con ciclos de conferencias ou, cando menos, unha a modo de clausura que impartía un destacado galeguista. En realidade, todos estes cursos tiñan os seus antecedentes naqueles que realizaba o Centro Galego de Madrid, entre 1959 e 1962 impartidos por Ramón Lorenzo e despois por Xosé Ramón Fernández-Oxea ${ }^{6}$. Non deixa de ser significativo que houbese que agardar ata a década dos sesenta para que o galego se convertese por primeira vez na historia do país en obxecto de estudo:

Unha das manifestacións máis interesantes do aitual rexurdir cultural de Galicia témola, de certo, nise interés crecente da mocedade polo estudo da nosa lingoa ${ }^{7}$.

En 1971 créase, dentro da Universidade de Santiago de Compostela, o Instituto da Lingua Galega (ILG), que organizou cursos en solitario, pero tamén en colaboración con moi diversas asociacións. O primeiro tivo lugar o mesmo ano da fundación na Coruña e a este seguirían outros moitos ata finais dos anos setenta, coa entrada do galego no ensino:

Conscientes de que tamén hai que alfabetizar ó resto da sociedade, e non só ós mestres, pra logra-la normalización lingüística, o ILG organizou cursos abertos en distintas cidades. Así, dentro dos cursos de vran celebráronse xa no ano 1971 dous cursos de galego na Coruña; en 1972, en Santiago; en 1973 en Vigo; en 1974 en Vigo e Santiago; en 1975 en Santiago; en 1976 en Santiago e Vigo [...] Durante todos estes anos o Instituto supervisou a marcha de cursos de galego abertos que organizaban asociacións culturais ou de veciños en distintas localidades galegas, ó remate dos cales se lles entregaba ós que superasen as probas o diploma do ILG. Cómpre lembrar aquí, pola continuidade que mantiveron durante varios anos, á Asociación Cultural de Cambados, ós Amigos da Cultura de Pontevedra, á Agrupación Cultural de Vilagarcía e ó Seminario Conciliar de Santiago ${ }^{8}$.

Moitos destes colectivos levaban impartindo cursos con anterioridade, como a Asociación Amigos da Cultura de Pontevedra, que comezara a xeira en 1967. Aínda así, o apoio do ILG foi fundamental porque lles proporcionaba profesorado cualificado, un método de aprendizaxe anovador e un certificado avalado por un instituto universitario. Así se recolle o 17 de maio de 1973 nunha noticia do diario La Región, onde se informa da entrega a se-

5 Neste último mes iniciáronse as clases de literatura contemporánea a cargo de Marino Dónega Rozas.

6 En Barcelona os Cursos de Língoa e Literatura Galegas comezaron 018 de setembro de 1961 e nos seus comezos foron impartidos por Basilio Losada. Para máis información pódese consultar M. X. LAMA e H. GONZÁLEZ (ed.), Ramón Piñeiro e Basilio Losada. Do sentimento á conciencia de Galicia. Correspondencia 1961-1984, Galaxia, Vigo, 2009.

7 Véxase "Cursos de língoa galega", no 8, 1965, pp. 251-253.

8 C. GARCÍA, "Actividades do Instituto da Lingua Galega" en D. Kremer e R. Lorenzo (eds.), Tradición, actualidade e futuro do galego. Actas do Coloquio de Tréveris (13 a 15 de novembro de 1980), Xunta de Galicia, Consello da Cultura Galega, Santiago de Compostela, 1982, p. 30. 
senta e nove persoas ${ }^{9}$ dos certificados expedidos polo ILG despois de realizaren un curso na Agrupación Cultural Auriense. Tamén foi crucial a publicación dos materiais de apoio, de aí o enorme éxito do primeiro manual para o estudo do galego elaborado polo ILG, que supuxo dotar a sociedade dunha ferramenta útil e anovadora de aprendizaxe. Contou con tres volumes: Gallego $1^{10}$ (1971), Gallego 2 (1972) e Gallego $3(1974)^{11}$.

Con anterioridade o galego xa lograra pasar o limiar universitario, pois en 1962 creárase, na Facultade de Filosofía e Letras da Universidade de Santiago de Compostela, o Departamento de Filoloxía Románica, que non se poría en funcionamento ata o curso 1963-64 ${ }^{12}$. É a partir desta data é cando se poden cursar materias de galego na USC, impartidas por Ricardo Carballo Calero ${ }^{13}$, que na Aula Trasmagna da Facultade de Ciencias dá a primeira clase 013 de outubro e, desta maneira, queda inaugurado un novo camiño para a lingua. A partir de 1963 o alumnado de Filoloxía Románica comeza a ter tres horas semanais obrigatorias de Lingua e Literatura Galegas no derradeiro curso da carreira e con carácter opcional os alumnos que cursaban cuarto de Historia podíanse matricular na materia de Filoloxía Galaico-Portuguesa Medieval. Un ano despois a Facultade escindiuse en tres seccións: Historia, Filoloxía Románica e Filoloxía Moderna. En Historia desapareceu por completo a materia optativa, mentres que se establecen para as outras dúas licenciaturas tres materias de libre elección: Lingua Galega, Filoloxía Galego-Portuguesa Medieval e Literatura Galega, correspondentes ó primeiro, segundo e terceiro ano da especialidade respectivamente. No curso académico 1967-68 establecéronse as mesmas materias, pero con diferente reparto. Sen dúbida, a introdución do galego na universidade é un fito histórico, aínda que, como se pode observar, nestes primeiros anos perdera o seu carácter de obrigatoriedade. Un paso atrás que se veu mitigado cando en 1972 se crea a subsección de Galego-Portugués dentro da titulación de Filoloxía Hispánica. Nese ano tamén tivo carácter optativo a materia de Lingua Galega no $2^{\circ}$ curso da Escola Universitaria de EXB de Santiago e no curso 1973-74 xa era obrigatorio o estudo de galego na especialidade de Filoloxía, aínda que optativo nas outras ${ }^{14}$. Algúns alumnos que estaban nos últimos cursos de Filoloxía Románica, e fixeran ou estaban facendo estas materias co profesor Carballo Calero, daban voluntariamente clases de galego nalgúns centros, como no Colexio Rodríguez Cadarso.

ĺanse subindo chanzos importantes para a introdución da lingua no ensino, pero aínda non se alcanzara penetrar no que tiña carácter obrigatorio. Se isto fose posible o coñecemento do idioma chegaría á maioría da poboación en idade de escolarización e faría que

9 Entre os alumnos atopamos a Manuel Guede, Marcos Valcárcel ou X. L. Vázquez Monxardín.

100 Gallego 1 editou nun ano 16.000 exemplares e ata 1980 levaba vendidos ó pé de 60.000, o que nos indica a súa repercusión.

11 Elaborados por Xosé L. Couceiro, Ramón Lorenzo, Guillermo Rojo e Antón Santamarina.

12 Os primeiros licenciados en Filoloxía Románica pola USC son do curso 65-66, entre os que se atopa Antón Santamarina, un dos profesores dos primeiros cursos de galego.

13 Carballo Calero foi agregado interino ata que en 1972 pasou a ser catedrático de Lingüística e Literatura Galegas.

14 Para unha visión máis demorada pode verse R. CARBALLO CALERO, "O galego na Universidade", en 0 porvir da lingua galega, Círculo de las Artes, Lugo, 1968, pp. 39-46. 
o escolante adquirise a lectura e a escritura na súa propia lingua ${ }^{15}$. Non só era importante a alfabetización en galego e o coñecemento do idioma, senón o seu recoñecemento como lingua de educación e de cultura. Esta era a aspiración dunha parte da sociedade civil, pero os seus ecos de demanda precisaban resoar noutras institucións que mantivesen comunicación co goberno para avalar esa petición histórica. Por esta razón, o 19 de abril de 1966 un grupo de case trinta rapaces ${ }^{16}$, no nome da "mocidade galega"17, remiten un escrito á Real Academia Galega, que segundo as actas desta institución se arquivou sen dar contestación. Nel reclamábase que, como órgano máis representativo da cultura galega, a Academia debía tomar unha postura valente e pioneira nun momento decisivo para a historia de Galicia:

E sentímonos chamados a nos dirixir a vostedes non soio en nome de tal Mocedade, sinón ademáis, como voceiros de toda a xente de Galicia que, pola sua iñorancia e pola falta dunha laboura dirixida á sua redención, permanece arredada do acceso i exercicio dos seus dereitos humáns, un dos cales, e dos máis sagros, é o de se expresar en tódalas actividades da sua vida na língua en que se formóu a cultura dos seus antergos ${ }^{18}$.

Entenden que, ata ese momento, a RAG non tiña estado á altura do país, pois móstrase estática na súa áurea institucional e desenvolvendo un papel oficial que lle nega capacidade de execución. Esas son as acusacións máis frecuentes, motivadas polo fervedoiro de iniciativas e de reclamacións que se están dando en Galicia e noutros puntos da xeografía española e onde se bota en falta á RAG nestas proclamas. Esíxelles á corporación da rúa Tabernas da Coruña unha defensa clara do patrimonio de Galicia e, moi especialmente, no ámbito educativo:

Do mesmo xeito, e conocendo como conoce esa Corporación os criterios da UNESCO encol das culturas chamadas minoritarias, nada se fai nin se intenta facer nos medios oficiás a fin de que se estude e se acometa dunha vez a reforma do insino primario, outorgándolle ó noso idioma o sitio que por dereito lle corresponde nas escolas e centros de enseñanza de Galicia.

15 No curso 1967-68 a taxa de escolarización en Galicia era do $80 \%$, entre os 6 e os 11 anos. Na década dos sesenta houbo unha importante mellora no acceso á educación, que ata aquel momento era moi deficitaria. 16 Hai cinco firmas que non son recoñecibles. Entre as que se identifican atopamos membros da Asociación Cultural O Galo e do Facho. Da primeira aparecen as sinaturas dos directivos Xosé Mosquera Stoll, presidente, Enrique Morales Quintana, secretario, Xosé Brea López, tesoureiro, e Xesús García Devesa, arquiveiro. Tamén asinan as vogais $\mathrm{M}^{\mathrm{a}}$ do Carme Ríos Panisse e Adela Figueroa Panisse. Ademais aparecen as firmas de Xavier Rodríguez Castillo, José Alberto Corral, U. Labarta, Pura Barrio, Manuel Lorenzo, Arcadio López Casanova, Xesús Sanxuás Formoso, Mㅡㄴ Llanos García Castellanos, Manuela Corral Villar, Mㅡ Elena López Prado, Xoán Xosé Carmona, Ramiro Cartelle Álvarez, Xosé Luís Rodríguez Pardo, Manuel Caamaño Suárez, O. Varela Carnero e Alfonso Gallego, algúns deles membros da Agrupación Cultural O Facho.

17 Non sabemos se este documento está relacionado coa Mocedade Galega Universitaria Católica (MGUC). Nel hai mencións ó uso do galego na liturxia e un dos asinantes é o secretario da MGUC, Xavier Rodríguez Castillo, pero tamén é certo que este grupo, creado á volta de 1961-62, esmorecera en 1965. Véxase R. GURRIARÁN, Inmunda escoria, Xerais, Vigo, 2010, pp. 254-256.

18 Documento conservado na Real Academia Galega. 
A reclamación do galego na escola acompáñase tamén doutras, coma o emprego do idioma propio na liturxia. Por iso esixen a aplicación das normas do Concilio Vaticano Il e piden misas en lingua galega en tódalas aldeas e unha á semana, cando menos, en tódalas restantes igrexas de vilas e cidades. Dubidan da postura da RAG ó estar integrada por certos membros que se atopan afastados dos intereses da lingua e da cultura galegas. Os asinantes deste manifesto eran conscientes de que non abondaba coas súas reclamacións. De aí que se dirixisen a un interlocutor que si debera ter poder para levar a cabo as xestións e as peticións necesarias para seguir avanzando:

A Academia Galega débese dirixir formalmente ós Orgaísmos competentes do Goberno Español, propoñendo a reforma do insino primario en canto fai concretamente á enseñanza en língua galega e ó estudo da nosa cultura

Se seguimos as actas da Real Academia Galega, ata ese momento os pasos dados nesta dirección foran case nulos, pero a partir desta data comeza a agromar unha certa inquedanza. Así, seis meses despois de recibir este escrito, os membros da RAG moven ficha, aínda que a reboque, e dan inicio ás xestións para que o galego sexa lingua de estudo na escola. 018 de outubro de 1966 a Real Academia Galega diríxese á Euskaltzaindia para solicitar unha copia do escrito que eles enviaran ó Goberno español e no que pedían o recoñecemento oficial do éuscaro para tódolos grados de ensinanza ${ }^{19}$. A idea era redactar un documento análogo, que finalmente envían o 28 de febreiro de 1967. Neste escrito que a RAG remitiu ó Ministerio de Educación e Ciencia expresábase "o desexo de que o Departamento que tan acertadamente rixe se sirva adoptar medidas adecuadas para que a nosa lingua vernácula sexa obxecto de estudo en todol-os nivés docentes ${ }^{20}$. Desafortunadamente na RAG non se atopa o texto arquivado, pero non podía distar moito do enviado pola Euskaltzaindia ${ }^{21}$, pois serviu de base para a súa redacción. Inferimos que habería ideas que se repiten, coma o feito de que unha lingua a maiores é unha riqueza lingüística e que non pexa o coñecemento do castelán. Por iso se pide a súa incursión nas escolas e nos centros de instrución xeral:

Ello contribuiría, no sólo a refortalecer el idioma, sino también a mejorar considerablemente el nivel cultural de las poblaciones de habla vasca, haciendo posible el encauzamiento de sus estudios primarios en condiciones mejores que las existentes en la actualidad y, desde luego, más conformes con los métodos que la moderna pedagogía aconseja.

En atención a las consideraciones expuestas, la Academia de la Lengua Vasca, acordó por unanimidad con fecha 29 de julio pasado, dirigirse a V. E. en súplica de que se adopten por este Ministerio las medidas siguientes:

Implantación, a título experimental, de cursos de lectura y escritura en lengua vasca, en algunas Escuelas Nacionales de las Provincias de Álava, Guipúzcoa, Navarra y Vizcaya,

19 Reciben a copia da Euskaltzaindia o 22 de decembro de 1966.

20 Texto recollido na acta da sesión ordinaria da RAG celebrada o 12 de marzo de 1967.

21 A Euskaltzaindia era unha institución máis nova cá galega, pois nacera en 1918, pero máis forte porque contaba co patrocinio das Deputacións de Biscaia, Gipuzkoa, Gasteiz e Navarra. 
cursos que podrían correr a cargo de los propios Sres. Maestros, o personal colaborador adecuado designado al efecto por el Estado o por las Corporaciones locales. Estas clases serían de gran utilidad porque servirían para arraigar el conocimiento del idioma en quienes habituados a hablarlo, carecieran, con relación al mismo, de otros conocimientos que los adquiridos por vía de tradición oral. Pudieran dedicarse a la aludida finalidad, algunas de las horas de estudio aplicadas a la enseñanza de gramática y literatura.

Estableciendo, con carácter voluntario, así en estudios primarios como en la Enseñanza Media, de exámenes de lectura, traducción, escritura y análisis gramatical en lengua vasca, con mención en el certificado de estudios de grado correspondiente, del resultado favorable de dichos exámenes, en su caso. Dicha mención constituiría motivo de estímulo para los alumnos y podría ser invocada como circunstancia de mérito en determinados supuestos.

Creación por Orden Ministerial de escuelas primarias-piloto, dedicadas en régimen de experimentación, a la enseñanza bilingüe en castellano y vasco. La práctica ha demostrado que el cultivo conjunto de ambos idiomas, proporciona a los alumnos de habla vasca, no sólo una mejor comprensión de las materias de estudio, sino incluso, mayor capacitación para un más ponderado y profundo conocimiento del castellano. Un certificado de estudios primarios en enseñanza bilingüe sería deferido a la terminación de los cursos.

Implantación en cada una de las Provincias de Álava, Guipúzcoa, Navarra y Vizcaya, de centros filiales de Instituto, destinados a enseñanza secundaria en régimen bilingüe, a título también de experimentación. Estos centros, así como las escuelas-piloto a que se alude en el precedente párrafo, podrían actuar bajo la dirección o patronato de la Academia de la Lengua Vasca, de acuerdo con un plan especial de estudios aprobados por el Ministerio.

Creación en las Escuelas de Magisterio de Bilbao, San Sebastián, Vitoria y Pamplona, de cursos graduados de lengua, gramática y literatura vasca, con un grado elemental, de aprendizaje de la lengua y otro superior, de gramática y lectura de autores. Podrían acudir a estos cursos, entre otros, los Sres. Maestros que quisieran prepararse a las funciones de enseñanza a que se hace referencia en los precedentes párrafos, con objeto de adquirir 0 profundizar en su caso, los necesarios conocimientos del idioma.

Implantación en determinados centros universitarios y escuelas superiores, de cursos de lengua vasca de carácter voluntario ${ }^{22 .}$

A Euskaltzaindia pide incluso unha subvención con cargo ó Ministerio de Educación Nacional e Ciencia para levar a cabo a promoción e dirección dos centros de ensinanza, así como para a elaboración de material pedagóxico. Non sabemos se a tanto se atrevería a corporación galega, pero é moi probable que compartise moitas das peticións que se deixan ver nese escrito que serviu de base. Estamos convencidos de que se poría en valor a ensinanza bilingüe, porque esa foi unha das cartas que sempre xogaron para a implantación. Se repasamos a revista Grial número a número no período de 1966-67 comprobamos como proliferan os artigos con referencias ó bilingüismo e se abren debates interesantes

22 Documento firmado polo presidente en funcións, José María Lojendio, e o secretario Koldo Mitxelena en Bilbao 015 de novembro de 1966. Pódese consultar no boletín da Euskaltzaindia en 1968 e tamén en Internet na seguinte ligazón: http://www.euskaltzaindia.net/dok/euskera/52069.pdf. 
a raíz da tradución dunha conferencia do profesor A. Richard Diebold pronunciada en Londres. Para este autor nas sociedades en que hai dúas linguas en desigualdade os seus individuos presentan un "baixo coeficiente inteleitual", pero se o fenómeno se dá en sociedades desenvolvidas e con linguas ó mesmo nivel isto non ocorre. As reaccións a esta afirmación non se fixeron agardar e J. García Durán móstrase radicalmente en desacordo, unha liña de pensamento que empasta ben coa de boa parte do galeguismo, que confían no ensino bilingüe. Así 0 afirma Valentín Arias $^{23}$ en diferentes ocasións:

É tarefa moi urxente conquerir licencia pró ensino da língoa galega nas nosas escolas. A única que deben deprender os rapaces deica que iles teñan os nove ou dez anos. E logo, empezarlles co castelán; que será adeprendido polo método de sustitución e comparando ambas língoas ${ }^{24}$.

Apóstase pola alfabetización primeira na lingua inicial, para despois, a través desta, ir introducindo o castelán. Da mesma opinión son os membros do grupo de traballo de Londres que publican o "Plan Pedagóxico en Galego" en 1971 nas páxinas da revista Grial. A idea de utilizar o galego como vehículo para coñecer mellor a única lingua oficial nese momento é un argumento esgrimido constantemente e parece, cando menos para o caso da Euskaltzaindia, que a recepción por parte do réxime era favorable:

Sobre el principio de estas peticiones el señor Ministro, dando por sentada la necesidad del conocimiento perfecto del castellano y el interés extraordinario de la conservación y cultivo del vascuence, manifestó su acuerdo completo con los deseos de la Comisión. Se presentan únicamente algunas dificultades de tipo técnico, que espera podrán resolverse satisfactoriamente, dada la manifiesta buena voluntad y deseo de colaboración de todos. El Sr. Ministro indicó asimismo que peticiones análogas se habían recibido también de Cataluña y de la Academia Gallega, y que todas ellas se están estudiando con el mayor interés y cariño, esperándose que pronto puedan ser llevadas a la práctica ${ }^{25}$.

A noticia transcendeu ós medios de comunicación de inmediato e foi acollida de bo grao, incluso entre a prensa proclive á ditadura, o que auguraba un futuro próximo no que houbese espazo para o galego, o catalán e o éuscaro:

He leído que la Diputación de Guipúzcoa va a solicitar autorización para promover la enseñanza del vascuence en las escuelas públicas de la provincia. Creo que la empresa es hermosa y sugestiva y que la vieja lengua de los euskaros, fuerte, ingenua y casta florecerá en los labios de los niños vascos [...] Creo que el vascuence, como el vascongado, es algo que está ahí de modo natural y glorioso como todo cuanto es parte y sustancia de España. Por eso hay que contemplar, naturalmente, este problema, aunque tengamos

23 Valentín Arias fora alumno de Avelino Pousa Antelo e a el substitúeo na Escola Agrícola da Granxa de Barreiros (Sarria). No curso 1972-73 publicaba no Faro de Vigo a páxina semanal "O galego na escola", onde tiñan cabida textos escritos en galego por nenos e nenas de diferentes escolas primarias.

24 V. ARIAS, "A lingua galega na escola", en O porvir da lingua galega, Círculo de las Artes, Lugo, 1968, p. 29. 25013 de setembro de 1967 reúnese unha comisión da Euskaltzaindia co Ministro de Educación e Ciencia. Dela dáse noticia no Boletín e pódese consultar en Internet na seguinte ligazón: http://www.euskaltzaindia.net/ dok/euskera/52069.pdf. 
que acostumbrarnos a ejercer un arte tan primario y tan difícil como es la naturalidad. Es ridículo que un vasco puede creer que su lengua vernácula es un ingrediente de disensión nacional y es soberanamente cómica la actitud de esos patriotas que se sienten vejados por no entender una sola palabra de vascuence. Hay que huir de aldeanismos y prosopopeyas y de patrioterías y complejos ${ }^{26}$

O artigo aparece no diario $A r r i b a^{27}$ e está asinado por Cristóbal $P a ́ e z^{28}$, polo que en principio agardariamos unha recepción desfavorable pola introdución no ensino doutra lingua que non fose o castelán. Aínda que as frases son ambiguas, despréndese unha predisposición a que o éuscaro sexa estudado nas escolas. Tendo en conta o medio no que aparece a información, a esperanza de conseguir que este paso se executase parecía máis preto. Ese ambiente de optimismo non era alleo á sociedade como se reflicte neste novo escrito enviado á RAG:

A "AGRUPACIÓN CULTURAL AURIENSE", a "ASOCIACIÓN CULTURAL DE VIGO" e a "AGRUPACIÓN CULTURAL "O FACHO", todas elas legalmente constituídas e domiciliadas nas cidades de Ourense, Vigo e A Cruña, respeutivamente, representadas polos seus directivos firmantes da presente, e tendo en conta que, novamente, volve estar en xogo 0 porvir e posibilidades da lingua e cultura do noso País, teñen a honra de se dirixir a vostedes pra lles espoñer as suas arelas, agardando unha comprida e satisfautoria resposta pola parte de vostedes xa que, dito seña no máis fondo respeto ó seu parecer, entendemos necesaria a sua inmediata acollida e, polo tanto, a posta en actividade das suxerencias que lles espoñemos ou daquelas outras que vostedes vexan máis axeitadas. [...] 0 do insino do idioma galego nas escolas primarias como língua de cultura e de conocimiento, tan só un tímido acordo académico, adoutado con posterioridade ós da Academia de Língua Vasca e do Institut d'Estudis Catalans, a unha instancia dirixida ó Ministerio de Educación e Cencia i encabezada polo Prof. Isla Couto, enchen a actividade galega nestes dous anos longos.

A favorable predisposición que no actual Director Xeneral de Insino Primario, Don Eugenio López e López, parece atopar o fenómeno das língua minoritarias españolas e o problema didáctico do bilingüísmo infantil, úrxenos a lles pregar que, do xeito que reglamentariamente seña oportuno, tome esa Academia en consideración estas novas posibilidades e, a título meramente indicativo, se acometan os seguintes puntos ou aqueles outros que, en relación co devandito problema, coiden vostedes precisos:

1‥- Creación dunha Comisión Académica que, coa colaboración de lingüistas, sociólogos e pedagogos de todo tipo, acometa a realización dun estudo sobre do insino do galego nas escolas, e poida, chegando o intre, preparar os textos escolares e programas pedagóxicos referidos a tal fin.

260 artigo completo titulado "El vascuence" pode lerse no diario Arriba, 28 de outubro de 1966, p. 3.

27 Arriba era o órgano xornalístico oficial de Falanxe Española. Fora fundado en Madrid como semanario 021 de marzo de 1935 por José Antonio Primo de Rivera. A partir de 1939 converteuse no xornal do Movemento Nacional e noprincipal diario da Cadena de Prensa do Movemento.

28 Cristóbal Páez nacera en Murcia en 1920. Era xornalista, doutor en Dereito, mestre nacional e diplomado en Dereito agrario, segundo consta no seu currículo. Ingresou en Arriba en 1945, onde ocupou diferentes cargos, ata que en 1975 se converteu no seu director. Estes e outros datos saen no artigo "Cristóbal Páez tomó posesión como nuevo director de Arriba" (ABC, 20 de febreiro de 1975, p. 38). 
2ํ.- Indicación dos oportunos contactos co Ministerio de Educación e Cencia, na persoa do Director Xeneral de Insino Primario, co fin de axuntar esforzos e actividades e lograr as financiacións precisas pra o desenrolo da tarefa señalada denantes.

3․-- Recabar a adhesión e colaboración de todas as Institucións Culturás de Galicia, tanto oficiás como privadas, dirixida a acadar un eco positivo no Ministerio de Educación e Cencia, así como noutro momento, pra desenrolar o traballo a que se refire o punto 1ㅇ; colaboración na cal crémos que, forzosamente, deberán estar presentes a Universidade e o Consello Económico Sindical29.

Nesta ocasión a Real Academia Galega responde o 15 de febreiro de 1969 ás asociacións asinantes, indicando que están a realizar as xestións que demandan. En concreto, no que se refire ó terceiro punto, diríxense ó Reitor da Universidade de Santiago de Compostela para obter o seu apoio e así exercer unha maior presión no goberno. Coa suma de forzas pretenden conseguir que a próxima lei educativa introduza as linguas vernáculas no ensino. Así, escríbenlle ó reitor:

La Academia siguió con toda atención el pujante desarrollo literario gallego en los últimos decenios, al que en todo momento prestó su apoyo, y registra con satisfacción el creciente interés por el estudio de la lengua regional, interés que ha dado lugar a la organización de cursos de gallego en diversas ciudades de Galicia y en otras de fuera de nuestra región (Madrid, Barcelona, Buenos Aires, Montevideo), en las que las colonias gallegas alli existentes sintieron la misma necesidad. La Academia se complace en señalar que para el desenvolvimiento de este interés por la lengua ha sido un hecho feliz la incorporación activa de la Universidad de Santiago, ya que al incluir en su reciente Sección de Románicas el estudio científico del gallego contribuye de modo fundamental a la preparación técnica de quienes están llamados a satisfacer las necesidades docentes de la lengua regional.

Más, si este panorama general es profundamente esperanzador para el futuro de la lengua y de la literatura gallega, en estos momentos la preocupación de la Academia se centra en la inminente discusión y consiguiente aprobación de una nueva Ley de Enseñanza en la que se fijará la situación legal de las lenguas vernáculas en relación con la enseñanza. Fiel a los fines para los que fue creada y a su propia historia, la Real Academia Gallega siente el deber ineludible de procurar una defensa oficial de los legítimos derechos de nuestra lengua.

Movidos por esta responsabilidad, que a diario nos estimulan las exhortaciones de entidades y personalidades gallegas igualmente preocupadas por el problema, nos dirigimos al Rector Magnífico de nuestra Universidad para expresarle nuestro deseo y nuestra esperanza de que, como representante máximo de la misma y como miembro de la Comisión Dictaminadora, defienda en el seno de dicha Comisión la incorporación de las lenguas vernáculas a la enseñanza, ya que una enseñanza racional, es decir, inspirada en los principios de la ciencia pedagógica, no puede prescindir de la realidad lingüística. [...] Lo que queremos es algo tan sencillo, tan natural, tan justo, que ningún espíritu libre de

29 Este documento atópase na Real Academia Galega. Está asinado a 1 de novembro de 1968 polas tres agrupacións culturais. 
prejuicios podrá dejar de comprenderlo y de aceptarlo: que se tenga en cuenta la realidad lingüística y que se parta de ella; que a los niños gallego-hablantes no se les violente en su personalidad espiritual y expresiva y que se les enseñe el castellano partiendo de su lengua materna. Al mismo tiempo, teniendo en cuenta que la lengua y la cultura gallegas forman parte de la realidad cultural española, consideramos justo y patriótico que sean incorporadas a los distintos niveles de enseñanza en Galicia. Nada más normal30.

Estas iniciativas tomáronse unha vez que se coñeceu o informe La educación en España: bases para una política educativa, elaborado pola Secretaría Xeral Técnica do Ministerio de Educación e Ciencia ${ }^{31}$. Este documento, coñecido como o Libro Branco, é o primeiro texto crítico sobre o ensino e nel indicábanse as deficiencias do sistema, pero tamén se adiantaban propostas para levar a cabo unha importante reforma e obter mellores resultados. $O$ texto foi moi ben acollido polas academias:

Esta Academia de la Lengua Vasca, consciente de los problemas derivados del bilingüismo, ha efectuado conversaciones y contactos de carácter técnico con la Real Academia Gallega y el Institut d'Estudis Catalans, llegando en principio a un acuerdo de base sobre una precisa ampliación de los criterios del Libro Blanco sobre el problema mencionado.

Por ello y considerando: entendemos que la enseñanza de la lengua vernácula habría de ser obligatoria para todos los niños nacidos o residentes en una de las regiones nominadas «bilingües", puesto que los niños en estas regiones, en sus primeros años, monolingües, salvo casos especiales en que el padre y la madre sean de diversa lengua nativa, es decir, que en la mayoría de los casos, la única lengua arraigada íntimamente en el espíritu infantil de las referidas regiones es la vernácula. Los valores de esta intimidad son tan profundos que la pedagogía moderna recomienda sin vacilación, el uso y estudio de la vernácula, como el mejor vehículo para la enseñanza primaria; y aun más, recomienda el uso de la lengua materna, hasta el grado más elevado posible de la formación intelectual, según declaró el equipo de psicólogos y pedagogos de la UNESCO, en la monografía titulada Empleo de las lenguas vernáculas en la enseñanza (edición en español, Lucerna, 1954), de la cual extractamos esta afirmación: «La lengua materna debería ser empleada como medio de instrucción hasta el más alto grado posible de enseñanza»; "Las autoridades deberían hacer todo lo que esté a su alcance para crear condiciones que permitan extender cada vez más el empleo de la lengua materna a la segunda lengua lo más suavemente posible y del modo menos perjudicial desde el punto de vista psicológico» (pág. 55). "La lengua materna es el medio natural de expresión de una persona, y una de sus primeras necesidades es desarrollar al máximo su aptitud para expresarse»: «Todo alumno deberá comenzar sus cursos escolares en la lengua materna»; "Si la lengua materna es adecuada en todos respectos para servir de vehículo de instrucción en las universidades y establecimientos de enseñanza, debe emplearse como tal» (pág. 75).

Posteriormente al estudio de la lengua materna o vernácula, cabría emprender en la

30 A Real Academia Galega escríbelle ó Reitor da USC en 1969. Este documento gárdase na Fundación Penzol. 31 Este texto foi publicado o 12 de febreiro de 1969. O novo ministro de Educación, Villar Palasí, tecnócrata ligado ó Opus Dei, apostou por levar a cabo unha importante reforma xeral no ensino e para iso precisaba un estudo serio que diagnosticase as eivas do sistema. 
segunda lengua -la castellana en nuestro caso-, la cual no sólo no sería obstaculizante por el uso de la vernácula, sino que, al contrario, resultaría favorecida, porque el previo estudio metódico de la lengua materna serviría al niño como punto de comparación, que facilitaría la captación de las diferencias y matices que distinguirían las dos lenguas. Los especialistas de la UNESCO formulan estas nociones, que dicen: «Si la lengua materna del niño no es la lengua oficial de un país, o una lengua mundial, necesita aprender una segunda lengua. Es posible adquirir un buen conocimiento de la segunda lengua sin emplearla como medio de instrucción general. Durante el primer año, o el segundo, de asistencia del niño a la escuela, el estudio de la segunda lengua puede ser introducido como asignatura. La enseñanza de la lengua debe progresar gradualmente y no se debe emplear como medio de instrucción hasta que los alumnos estén suficientemente familiarizados con ella» (pág. 76).

El aprendizaje de dos lenguas facilitaría a su vez el de terceras lenguas, en nuestro caso del vascuence: uso del partitivo, además de otras formas gramaticales, leyes fonéticas, especialmente valores fonológicos: $\mathrm{j}, \mathrm{x}$, ts, tt, tx, etc., más la concordancia del léxico. Estos $y$ otros detalles similares ayudarían al aprendizaje de otras lenguas en tiempo breve. Prescindir del estudio metódico de nuestras lenguas vernáculas significa limitar y entorpecer esta facilidad para el conocimiento del español mismo, así como de otras lenguas. Todo lo expuesto expresa nuestro punto de vista sobre el párrafo primero del número 20 de las «Bases para una política educativa», para las modificaciones pertinentes ${ }^{32}$.

Estas consideracións, asumidas polas tres institucións e enviadas ó Ministerio de Educación e Ciencia, seguían na liña de presión para a introdución do galego, do catalán e do éuscaro no ensino, porque sabían que se estaba a elaborar nese ano 1969 a Lei Xeral de Educación (LXE). A RAG tiña a un dos seus membros, Xosé Fernando Filgueira Valverde, entre os procuradores en Cortes que podían propoñer emendas e tamén contaban coa axuda de Antonio Rosón ${ }^{33}$. Grazas ó labor arquivístico de Ramón Piñeiro e Francisco Fernández del Riego consérvanse na Fundación Penzol as emendas que propuxeron. Filgueira Valverde refírese á Sección II, Artigo 17 e apartado 1ํ do proxecto de Lei Xeral de Educación para que quede redactada da seguinte maneira:

b) Dominio del lenguaje como base de toda formación. Estudio de la lengua nacional. Iniciación en el aprendizaje de una lengua extranjera. En las áreas bilingües, el idioma de la región será utilizado como habla vehicular para la enseñanza del castellano y cultivado como manifestación viva de nuestro patrimonio espiritual, artístico y literario.

Na xustificación que engade no escrito a continuación da emenda pídese que o emprego da lingua inicial, neste caso o galego, debe ser o vehículo de aprendizaxe de calquera outra lingua, pois xa así o recomendaban os pedagogos do $\mathrm{s}$. XVIII ${ }^{34}$ e tamén os actuais. Amais desta maneira podíase evitar 0 autoodio á lingua propia. Así mesmo, o pontevedrés

32 Este documento foi asinado en Andoain o 19 de abril de 1969 e remitido ó Ministro de Educación e Ciencia. Foi recollido en 1971 no Boletín da Euskaltzaindia e pode consultarse en Internet na seguinte ligazón: http://www. euskaltzaindia.net/dok/euskera/52010.pdf.

33 Antonio Rosón era moi amigo de Ramón Piñeiro e sería o primeiro Presidente do Parlamento autonómico de Galicia.

34 Filgueira Valverde pensaba en Frei Martín Sarmiento. 
pedía que a lingua galega estivese presente no Bacharelato e non só no ensino obrigatorio, pois é lingua na que escribiron reis como Afonso $X$, unha referencia que o polígrafo pontevedrés non quere deixar pasar nesta emenda ${ }^{35}$.

Pola súa banda, o procurador en Cortes Antonio Rosón fai varias emendas nas que pide incluír en preescolar a lingua vernácula ${ }^{36}$, e, concretamente, no artigo 17 propón incorporar a carón do estudo da lingua nacional "en las Regiones bilingües, estudio de la lengua vernácula la cual se empleará también, especialmente en la primera etapa, como medio de instrucción". Na súa xustificación ampárase nas mesmas citas que se inseriron no escrito asinado en Andoian en 1969 e que foi reproducido neste artigo. Entre os papeis atopados na Fundación Penzol hai dous folios remitidos a Rosón, posiblemente por Ramón Piñeiro, nos que se recollen algúns dos principios fundamentais establecidos no informe da UNESCO Empleo de las lenguas vernáculas en la enseñanza ${ }^{37}$. Insístese neste artigo dirixido a Rosón en que a UNESCO adoptou como principio a doutrina do bilingüismo na ensinanza cando os países teñen dúas linguas e España, como membro deste organismo, debe aceptar a validez deste principio pedagóxico:

España es un país en el que se hablan y se cultivan literariamente cuatro lenguas distintas: castellano, gallego, catalán y vascuence. Cada una de estas lenguas -como toda lengua- es la expresión de una personalidad espiritual colectiva, es decir, de una cultura peculiar, y el conjunto de las cuatro constituye el patrimonio cultural español, que el Estado tiene el deber de garantizar y proteger en su normal desarrollo. Los principios establecidos por la ciencia pedagógica universal son igualmente claros: en los países bilingües, la enseñanza ha de llevarse a cabo partiendo de la lengua materna. Es decir, los niños españoles cuya lengua materna no sea el castellano, deberán aprender el castellano a través de su propia lengua. Ha de respetarse la personalidad espiritual y expresiva del niño y hacer que, desde ella y no contra ella, aprenda bien la lengua nacional. Esta honda experiencia infantil tendrá un positivo alcance patriótico por cuanto en la formación misma de su personalidad tendrá la vivencia del respecto, la convivencia y la fraternidad espiritual española.

Para hacer, pues, congruentes los datos de la realidad española y los de la ciencia pedagógica dentro de la Ley de Enseñanza, ésta deberá establecer expresamente el principio de la incorporación de las lenguas vernáculas a la enseñanza. Haciéndolo así nos pondremos a la altura de los tiempos, favoreceremos el desarrollo cultural español y contribuiremos al surgimiento de un nuevo patriotismo basado en la fraternidad, porque habremos evitado la discriminación espiritual de los españoles por motivos tan entrañables como la lengua. De esta forma, la lengua oficial -el castellano- gozará del amor de todos, porque todos la aprenderán desde su propia lengua y no habrá en ello choque psicológico ni resentimiento alguno.

Quédanos o traballo de cotexar no Ministerio de Educación os documentos que foron enviados, pero con esta pequena cala podemos ter unha idea de por onde ían as peticións

35 A emenda está asinada o 12 de novembro de 1969 e o texto consérvase na Fundación Penzol.

36 Refírese ó artigo 14.1.

37 Citan pola edición española, publicada en 1954, tres anos despois da reunión, para elaborar o informe. 
e en que se baseaban para xustificalas. O certo é que a Lei Xeral de Educación foi aprobada en 1970 con importantes propostas, tamén no que respecta ó ensino da lingua galega. Así quedaron redactados finalmente os artigos que incluían a posibilidade do ensino das outras linguas do Estado:

Artículo catorce.

Uno. La educación preescolar comprende juegos, actividades de lenguaje, incluida, en su caso, la lengua nativa, expresión rítmica y plástica, observación de la naturaleza, ejercicios lógicos y prenuméricos, desarrollo del sentido comunitario, principios religiosos y actitudes morales.

Artículo diecisiete.

Uno. Las áreas de actividad educativa en este nivel comprenderá: el dominio del lenguaje mediante el estudio de la lengua nacional, el aprendizaje de una lengua extranjera y el cultivo, en su caso, de la lengua nativa.

Coa implantación da $\mathrm{LXE}^{38}$ existía a posibilidade de impartir a materia de lingua galega, aínda que de maneira marxinal e só no ensino xeral básico, polo que habería que agardar ó Decreto 1433/1975, do 30 de maio, para que se desenvolva máis esta cuestión:

Artículo I.- Se autoriza a los Centros de Educación Preescolar y Educación General Básica, con carácter experimental, y a partir del curso mil novecientos setenta y cinco-setenta y seis, para incluir en sus programas de trabajo, como materia voluntaria para los alumnos, la enseñanza de las lenguas nativas españolas.

Artículo II.- Las enseñanzas en estos Centros tenderá a asegurar el fácil acceso del castellano, lengua nacional y oficial, de los alumnos que hayan recibido otra lengua española como materia, así como a hacer posible el conocimiento de esta última y el acceso a sus manifestaciones culturales a los alumnos que la soliciten.

No curso 1972-73 acolléronse sesenta e unha escolas e case un milleiro de alumnos á posibilidade dun ensino en galego. Nesta primeira época podían empregar como material o libro Lecturas galegas I (1972), editado por Galaxia e feito dende o Instituto da Lingua Galega. No ensino medio algúns institutos optaron por organizar cursos que cada vez tiñan máis éxito: o primeiro ano foron só trece institutos, ó ano seguinte dezaoito e xa no ano académico 1973-74, despois de que se introducira nos cursos $5^{\circ}$ e $6^{\circ}$, pasou a ser materia optativa no curso de acceso á universidade, en COU. A partir de 1975 xeneralizáronse os cursos de lingua galega en case tódolos institutos de Galicia e neste espallamento tivo moito que ver o labor do ILG, pois entre 1975 e 1980 formaron nos seus cursos a máis de 5.200 mestres. Naquel momento os profesores non tiñan formación, aínda que para moitos deles fose a súa lingua inicial, pero non estaban alfabetizados nela, polo que os cursos

38 Para levar a cabo a implementación da LXE, aprobouse a Planificación de la Educación en Galicia (1970). Neste plan recoñecíanse unhas taxas de escolarización inferiores á media do Estado, tíñase en conta a dispersión xeográfica e aceptábanse unhas taxas de fracaso escolar superiores, do que se infería que era debido á existencia dunha lingua propia. 
de formación foron imprescindibles. Tampouco contaban con moitas ferramentas das que botar man, aínda que cada vez son máis frecuentes materiais como Picariños ${ }^{39}$, editado en 1975, e que vai ser o primeiro método de lectura e escritura en galego; en 1977 a editorial Anaya publica a serie de libros de texto de galego "Lúa Nova", materiais que van apoiar 0 labor dos docentes.

Ó final da década dos setenta agroma un panorama esperanzador coa implantación dun réxime democrático e albíscase a autonomía para Galicia, ó tratarse dunha das nacionalidades históricas. Chegado o momento había moito camiño feito, especialmente aboado na década dos sesenta e dos setenta con reivindicacións como as que se amosaron nestas páxinas: cursos, elaboración de material, introdución do galego no ensino primario, secundario e na universidade... As demandas foron concretándose coa aprobación do Estatuto de Autonomía de Galicia (1981) e a Lei de Normalización Lingüística (1983), pero o período autonómico soborda xa a época de estudo fixada neste artigo. 